\title{
MODELING OF THE TENSOMETRIC MEASURING SYSTEM
}

\author{
Jozef NOVOTŇÁK*, Miroslav ŠMELKO, Rudolf ANDOGA, Pavol LIPOVSKÝ, Martin \\ FIL'KO
}

Technical university of Košice, Faculty of Aeronautics, Rampová 7, 04121 Košice, Slovak Republic

*Corresponding author. E-mail: jozef.novotnak@tuke.sk

\begin{abstract}
Article deals with the design of a model of a tensometric measuring system. Authors in this article describes the procedure for measuring the system response to a step change in load and then the procedure creating a model. The article shows a graphical comparison between the measured ones system characteristics and simulated system characteristics. The conclusion is given calculated errors between measured system characteristics and simulated system characteristics.
\end{abstract}

Keywords: tensometric measuring system; system modeling; measuring system response; system identification

\section{INTRODUCTION}

The unmanned air vehicles (UAVs) are currently very popular and are used in various industries. Various autopilot platforms are placed aboard these UAVs. These autopilot platforms provide partially or fully autonomous flying depending on the selected mode or flight mode. The basic autopilot algorithm consists of PID controllers that are used to control and stabilize the flight. The goal of these PID controllers is to minimize errors over time. The values of individual controllers can be set using software to improve UAV management. In order to set these controllers, it will be necessary to know the UAV model and therefore a measurement system has been designed to measure UAV control [1]. To create the UAV model, it is necessary to identify the characteristics of the measurement system [2] and then create a model of this system to verify the functionality of the measurement system.

\section{MEASURING THE RESPONSE OF THE SYSTEM}

During the measurement of the system response to the step change load, the system was loaded with a weight at the center point during the measurement. This change is expressed by the output value of the $\mathrm{AD}$ converter, which is given in bits. We repeated the measurements at different loads to obtain the system output characteristics and the system transfer function.

The output characteristic of the system (Figure 1) exhibits an initial oscillation, which has stabilized over time. This oscillation was caused by the movement of the weight after it was suspended. This condition can be compensated by first loading the measuring system and removing the weight during the measurement. In such a procedure, the output characteristic does not show oscillation and thus is a first order system, since it also does not have an inflection point $[3,4,5]$.

The transfer function of the system (Figure 2) shows that the system is linear. From the measured data in steady mode (without oscillation), the resolution of the measuring system and the gain of the system were calculated from the average values at the output of the individual sensors. 




Figure 1 Graph of system load step function with a weight

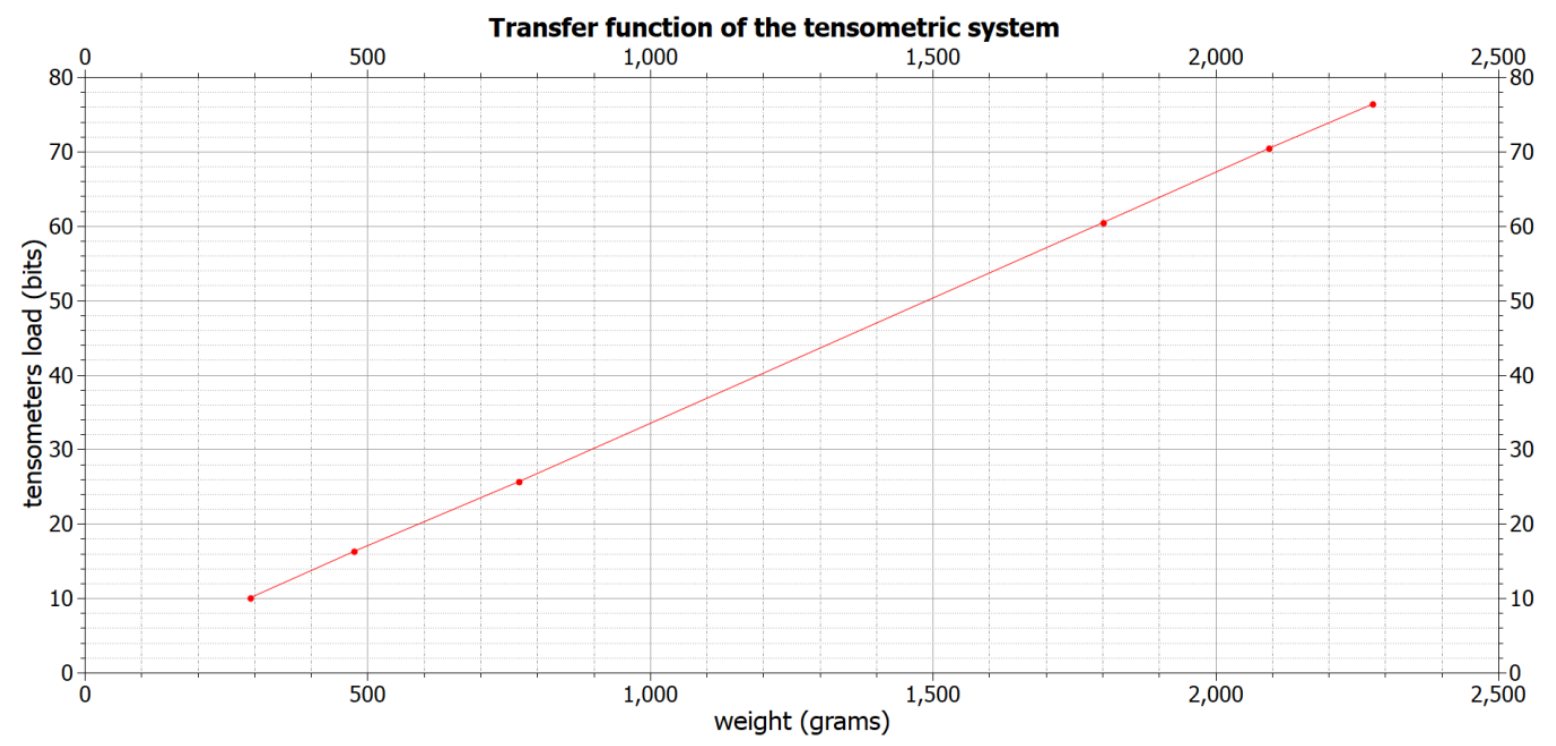

Figure 2 Graph of transfer function of the tensometric system

The resolution of the measuring system is 29,6769 grams/bit. We have determined this from the following equation:

$$
\text { Resolution }=\frac{L W}{\text { Oavg }}
$$

where $L W$ is the load weight and Oavg is the average system output value of the sensors in bits. This describes the following equation:

$$
\text { Oavg }=\frac{\sum_{n=1}^{8} O n}{8}
$$

where $O n$ is the output value of the particular sensor in bits. 
After calculating the resolution, we determined the gain of the system $(K)$ that is $[3,5]$ :

$$
K=\frac{1}{\text { Resolution }}=\frac{1}{\frac{L W}{\text { Oavg }}}=\frac{\text { Oavg }}{L W}
$$

Given the average system output value of the sensors, we have determined the gain correction $(K c)$ of particular sensors from the following equation:

$$
K c=\frac{O a v g}{O n}
$$

The calculated gain corrections for particular sensors are shown in the following table:

Table 1 Gain correction of particular sensors

\begin{tabular}{|c|c|c|c|c|c|c|c|c|}
\hline Sensor number & 1 & 2 & 3 & 4 & 5 & 6 & 7 & 8 \\
\hline Gain correction & 0,9919 & 1,0007 & 1,0014 & 1,0112 & 0,9901 & 1,0114 & 1,0031 & 0,9901 \\
\hline
\end{tabular}

\section{THE DESIGN OF THE BASIC MODEL OF THE MEASURING SYSTEM}

When designing the model of the measuring system, we have taken precisely the data obtained so far. In addition to these data, it was also necessary to determine the transfer function $(G(s))$ for each sensor. Since it is a first order system, we are based on the following equation $[3,4,5]$ :

$$
G(s)=\frac{K}{T s+1}
$$

where $K$ is the gain of the system and $T s$ is the time constant of the system we have determined from the normalized graph of system load step function (step started at 0 time) at value $0,63 y[3,4,5]$ :

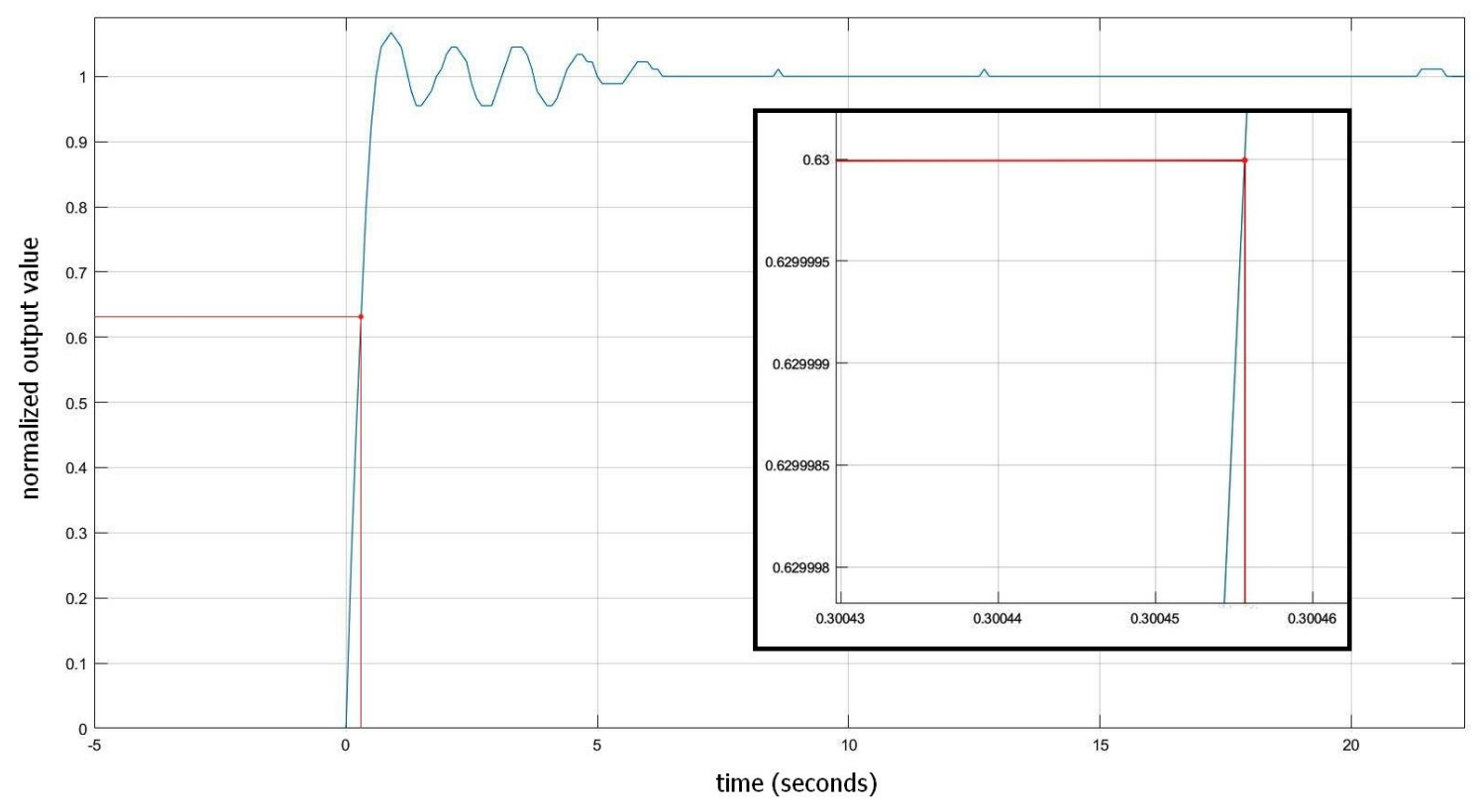

Figure 3 Determining the system time constant 
The time constant subtracted from the graph (Figure 3) is around 0,300456 seconds. The transfer function is now given by the following equation:

$$
G(s)=\frac{\frac{1}{29,6769}}{0,300456+1} . K c
$$

where $K c$ is gain correction of particular sensors according to the Table 1. Based on this data, we have designed a measurement system model.



Figure 4 Measuring system model

\section{COMPARISON OF MEASURED AND SIMULATED DATA}

After designing the basic model, it was possible to compare the measured system characteristics with the simulated system characteristics and then to calculate model errors. The graphical representation of the measured characteristic and simulated characteristic for one of the sensors shows the following figure: 


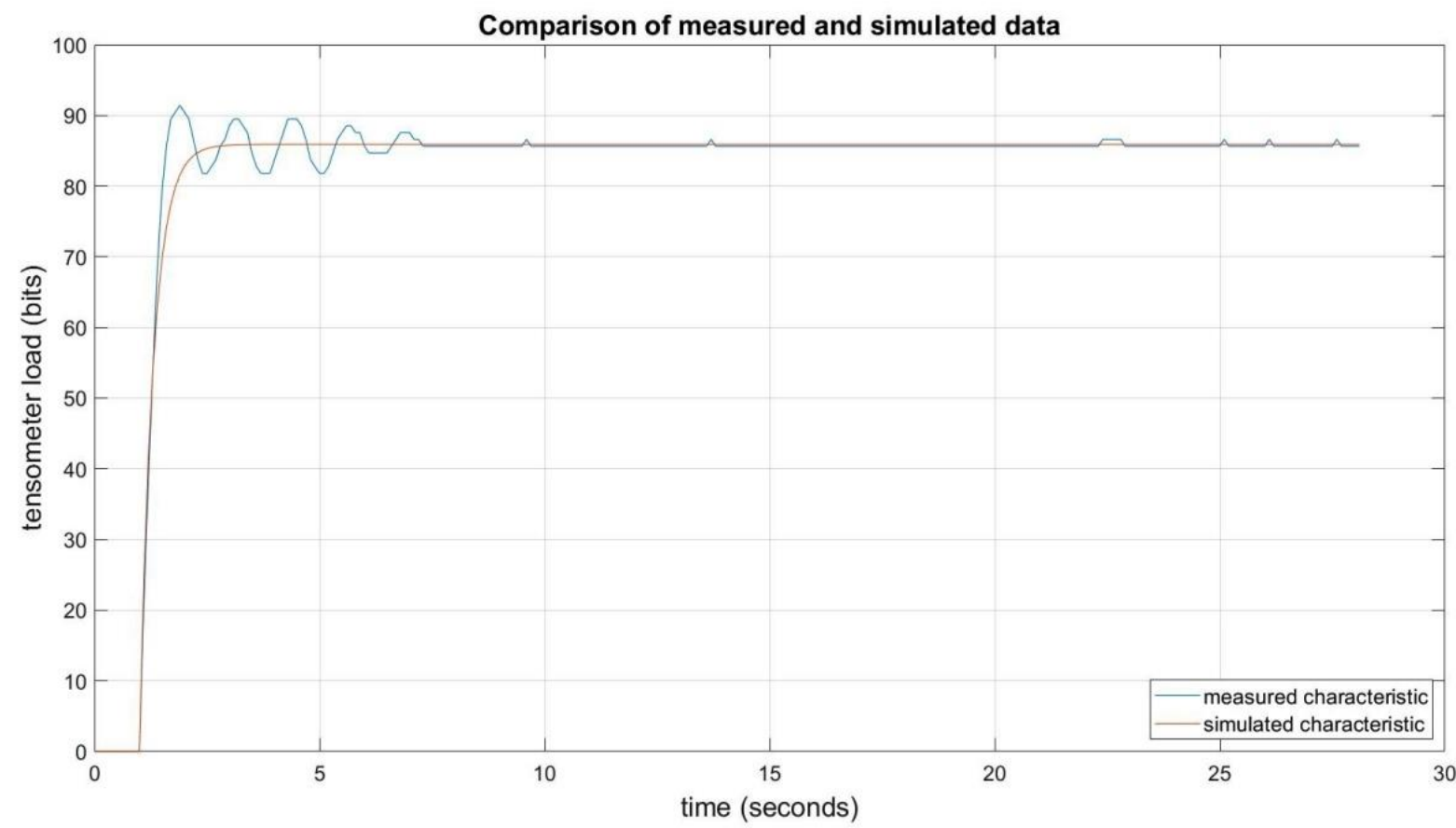

Figure 5 Comparison of measured and simulated data for one of the sensors

Since the model of the measuring system is to be used to verify the functionality of the measuring system, we will only consider the steady part of the characteristic when calculating model errors. When evaluating model errors, we focused on MAAE (Maximum Absolute Error), MAE (Mean Absolute Error), and MAPE (Mean Absolute Percentage Error) [6, 7]. The following table shows an overview of the calculated model errors from the steady part of the characteristic:

Table 2 Calculated model error for steady state of the characteristic for one of the sensors

\begin{tabular}{|c|c|c|c|}
\hline \multirow{2}{*}{$\begin{array}{c}\text { Sensor } \\
\text { number }\end{array}$} & \multicolumn{3}{|c|}{ Model errors } \\
\cline { 2 - 4 } & MAAE & MAE & MAPE \\
\hline 1 & 0,7188 & 0,2646 & 0,3084 \\
\hline 2 & 0,9933 & 0,1300 & 0,1511 \\
\hline 3 & 0,0640 & 0,0640 & 0,0738 \\
\hline 4 & 0,8927 & 0,2563 & 0,2942 \\
\hline 5 & 0,0753 & 0,0753 & 0,0879 \\
\hline 6 & 0,8800 & 0,2852 & 0,3271 \\
\hline 7 & 0,7388 & 0,2836 & 0,3264 \\
\hline 8 & 0,0753 & 0,0753 & 0,0879 \\
\hline
\end{tabular}




\section{CONCLUSION}

This paper describes the identification of a measuring system, the design of a measuring system model by measuring the response of a measuring system to a step change in load. The article describes how to measure the system response of the tensometric measuring system, the model creation process, and finally, the model error assessment for a step change in load. The model can be used to verify the functionality of the measuring system, i.e. when comparing the measured value of the system output and the estimated (simulated) value at the system output. At the end, the calculated errors between measured and simulated data are listed.

\section{ACKNOWLEDGEMENT}

This work was supported by the KEGA No. 052TUKE-4/2018, KEGA No. 058TUKE-4/2018, VEGA No. 1/0374/17, APVV-17-0184 and APVV-16-0079 projects. The authors would like to thank the project management and colleagues for support and valuable questions, remarks and suggestions.

\section{References}

[1] Fil'ko, M. Force gauge system for measurement of UAV control, Diploma thesis, Technical University of Košice, Faculty of Aeronautics, Košice. 2018.

[2] Noskievič, P. Experimentálni identifikace systemů, Modelováni a identifikace systému. MONTANEX. Ostrava. 1999. P. 122-130.

[3] Noskievič, P. Experimentální identifikace pomocí deterministických signálů, Modelováni a identifikace systému. MONTANEX. Ostrava. 1999. P. 173-174.

[6] MEAN ABSOLUTE PERCENTAGE ERROR (MAPE). In: Swamidass P.M. (eds) Encyclopedia of Production and Manufacturing Management. Springer, Boston, MA. 2000.

[7] Mean Absolute Error. In: Sammut C., Webb G.I. (eds) Encyclopedia of Machine Learning. Springer, Boston, MA. 2011.

[4] Niemann, H. - Miklos, R. A Simple Method for Estimation of Parameters in First order Systems, 2014. Journal of Physics: Conference Series 570 012001. Available at: https://iopscience.iop.org/article/10.1088/1742-6596/570/1/012001/pdf

[5] First Order System Types. The University of Jordan, Control Laboratory, Jordan. Available at: http://engineering.ju.edu.jo/Laboratories/04\%20-\%20First\%20Order\%20System.pdf

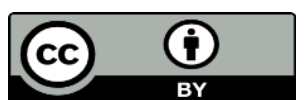

Article is licensed under a Creative Commons Attribution 4.0 International License 